دSCNT

Journal of Sustainable Construction

Materials and Technologies

J Sustain. Construct. Mater. Technol. 3(2) (2018) 235-241
Journal of Sustainable

Construction Materials

and Technologies

www.eds.yildiz.edu.tr/jscmt

\title{
Effect of Using Colemanite and Basalt Fiber on the Mechanical Properties of Metakaolin-Based Geopolymer Mortars
}

\author{
Nawar Ali ${ }^{1, *}$, Orhan Canpolat ${ }^{1}$, Mukhallad M. Al-mashhadani ${ }^{1}$, \\ Yurdakul Aygörmez ${ }^{1}$, Mucteba Uysal $^{2}$ \\ ${ }^{I}$ Yildiz Technical University, Faculty of Civil Engineering, Civil Engineering Department, Davutpasa Campus, \\ Istanbul, Turkey \\ ${ }^{2}$ Istanbul University, Engineering Faculty, Civil Engineering Department, Avcilar campus, Istanbul, Turkey
}

Manuscript Received February 3, 2018; Accepted April 11, 2018

\begin{abstract}
In the current studies which focus on the impact of $\mathrm{CO}_{2}$ emissions that released from the cement industry, showed the importance of finding alternative binders other than cement like geopolymer. This paper presented metakaolin based geopolymer which was manufactured by partially replacing metakaolin with colemanite with different percentages $(10 \%, 20 \%$, and $30 \%)$, to investigate the effect of colemanite on the mechanical properties of geopolymer. Then a comparison was carried out between non-fibrous specimens and basalt fiber reinforced ones to evaluate the improvement in terms of flexural and compressive strength of metakaolin-based geopolymer. The results showed that replacing metakaolin with $10 \%$ colemanite and adding $1 \%$ basalt fiber achieved $28.17 \%$ improvement in flexural strength at age 7 days compared to the reference sample.
\end{abstract}

Keywords: Geopolymer, Metakaolin, Colemanite, Basalt Fibers.

\section{Introduction}

The increase in consumption rate of cement came as a result of urbanization, and this led to an increase in cement production.

${ }^{*}$ Corresponding author:

E-mail address: nawarali1992@yahoo.com (Nawar Ali)

https://doi.org/10.29187/jscmt.2018.25 
The process of cement production needs huge amounts of raw materials, energy, and heat; also cement industry produces $7 \%$ of global carbon dioxide emissions and millions of tons of waste product cement kiln dust each year. The harmful impacts of cement industry create a need to find alternative and eco-friendly binder materials [1-4].

Geopolymer is an inorganic new binding eco-material. It was presented by Davidovits in 1978. The binding system of geopolymer is formed by the chemical reaction between the amorphous alumina-silicate materials and alkali solution, as a result of this reaction a three-dimensional polymeric chain structure consisting $\mathrm{Si}-\mathrm{O}-\mathrm{Al}$ bonds. Geopolymer has properties, which make it superior to other binder materials; low cost, quick compressive strength development, high temperature resistance and low energy consumption, also geopolymerization reaction could occur at room temperature, so producing geopolymer reduces the greenhouse emission significantly [5-9].

The binding materials in geopolymer are materials rich with silicate and aluminate and have pozzolanic property. They could be natural materials like zeolite, by-product materials such as fly ash and granulated blast furnace slag or product materials like metakaolin which resulting from dihydroxylation of kaolin at high temperature up to $650^{\circ} \mathrm{C}$. It was found that metakaolin-based geopolymers are more stable even when exposed to high temperature, reaches up to $700^{\circ} \mathrm{C}$, because calcined materials performed better in making geopolymer compared to natural ones [10-14].

Many of additions are used as performance optimizers to geopolymer, like fibers, which have a significant impact on the improvement of flexural strength of geopolymer. The effectiveness of fibers depends on type and size of fibers. In this context, many studies were made on the effects of fibers on the mechanical properties of geopolymers.

Behera et al. [15] investigated the properties of basalt microfibril geopolymer composites when exposed to elevated temperature $\left(200,400\right.$ and $\left.800{ }^{\circ} \mathrm{C}\right)$. It was found that the compressive strength of basalt microfibrils filled geopolymer was higher than the non-fibrous geopolymer due to pore-filling effect of basalt microfibrils, so denser microstructure. The study suggested that the basalt microfibrils filled geopolymer could be suitable for elevated temperature applications in thermal coatings

Rill et al. [16] studied the effect of basalt chopped fibers on the mechanical properties and microstructure of potassium-based geopolymer. Geopolymers were manufactured at ambient temperature and cured in a humidity controlled, constant temperature oven at $50{ }^{\circ} \mathrm{C}$. It was found the addition of even $1 \%$ wt of fibers did a small, though noticeable improvement to the strength. Basalt chopped fibers showed a high increase in flexural strength; also it was observed that the chopped basalt fiber helped to delay thermal cracking of geopolymer when exposed to high temperature up to $500{ }^{\circ} \mathrm{C}$.

Chen et al. [17] investigated the influence of curing temperature and time on the properties of metakaolin-based geopolymer. Conclusions showed, the compressive strength increases with the increasing of curing temperature, however the samples that cured at high temperature $\left(80^{\circ} \mathrm{C}\right.$ and $\left.100^{\circ} \mathrm{C}\right)$ lost a part of their own moisture, which is required for geopolymerization to develop the strength. The highest compressive strength was obtained at curing temperature $60^{\circ} \mathrm{C}$ for $168 \mathrm{~h}$.

Aponte et al. [18] carried out a study on physicomechanical characteristics of metakaolin-based geopolymer with added $\mathrm{TiO}_{2}$ particles. It was found that the highest strength was achieved by adding $10 \% \mathrm{wt} \mathrm{TiO}_{2}$, with $10.3 \%$ increase than the reference. This increase attributed to the small size of $\mathrm{TiO}_{2}$ particles, which enhance the formation of reaction products.

Boron is the most abundant waste material in Turkey, it exists in three forms: tincal, colemanite, and ulexite. Colemanite is a secondary mineral that forms by alteration of borax and ulexite. It is mostly used in ceramics industries; it has the ability to drop the melting temperature of the mixture and to prevent the crystallization [19]. There is a lack of studies made on the addition of colemanite and basalt fibers on metakaolin-based geopolymer.

This research focused on the sustainability and replacement materials, by using waste material like colemanite, as it is one of the most abundantly available in Turkey. The effect of replacing metakaolin with colemanite with different percentages and adding basalt fibers as an optimizer, on the compressive and flexural strength of metakaolin-based geopolymer have been investigated in this research.

\section{Experimental materials and methods}

\subsection{Materials}

Metakaolin was used to produce geopolymer in this research. It was brought from Kaolin Endustriyel Mineraller A.S., Turkey. The pozzolanic index of metakaolin was $1359 \mathrm{mgCa}(\mathrm{OH})_{2} / \mathrm{g}$. Colemanite was obtained from Eti Mine Bigadic Boron Works (Balikesir/Turkey). The chemical compositions of metakaolin and colemanite are shown in Table 1: 
Table 1. The Chemical Composition of Metakaolin and Colemanite

\begin{tabular}{ccccccccccc}
\hline Compound, \% & $\mathrm{SiO}_{2}$ & $\mathrm{Al}_{2} \mathrm{O}_{3}$ & $\mathrm{Fe}_{2} \mathrm{O}_{3}$ & $\mathrm{TiO}_{2}$ & $\mathrm{CaO}$ & $\mathrm{MgO}$ & $\mathrm{K}_{2} \mathrm{O}$ & $\mathrm{Na}_{2} \mathrm{O}$ & $\mathrm{B}_{2} \mathrm{O}_{3}$ & L.o.i 1000 \\
\hline Metakaolin & 56.10 & 40.23 & 0.85 & 0.55 & 0.19 & 0.16 & 0.51 & 0.24 & - & 1.10 \\
Colemanite & 4.00 & 0.40 & 0.08 & - & 27.00 & 3.00 & - & 0.50 & 40.00 & 25.00 \\
\hline
\end{tabular}

Alkali solution was prepared by mixing sodium silicate with sodium hydroxide (10M). Sodium silicate solution had the chemical composition $\left(\mathrm{Na}_{2} \mathrm{O}=8.2 \%, \mathrm{SiO}_{2}=27.0 \%\right.$ and water $=64.8 \%$ by mass $)$, on the other hand, sodium hydroxide solution was prepared by dissolving $\mathrm{NaOH}$ pellets ( $99 \%$ purity) in distilled water.

Also, basalt fibers were used in this research with a constant ratio ( $1 \%$ of binder mass). The technical properties of basalt fiber are shown in Table 2:

\section{Table 2. Properties of Basalt Fiber}

\begin{tabular}{ccccccc}
\hline Fiber type & Length $(\mathrm{mm})$ & Diameter $(\mu \mathrm{m})$ & Modulus of & Elongation & Tensile & Density $\left(\mathrm{g} / \mathrm{cm}^{3}\right)$ \\
\hline Basalt fiber & 12 & $13-20$ & 89 & 3.15 & $4100-4800$ & 2.80 \\
\hline
\end{tabular}

Standard sand (TS-EN 196-1) was added to the mix as fine aggregates.

\subsection{Sample preparation}

Geopolymer was manufactured within two stages; first $\mathrm{NaOH}$ pellets were dissolved in distilled water a day before with molarity (10M). The next day it was mixed with the $\mathrm{Na}_{2} \mathrm{SiO}_{3}$ solution to obtain the alkali activator. The solution was cooled at room temperature; later dry materials were mixed with alkali solution by a mechanical mixer for 3 minutes until getting a homogeneous mixture.

The reference sample was made with $100 \%$ metakaolin, one group of the samples were made with colemanite with different ratios as a partial replacement of metakaolin $(10 \%, 20 \%$, and $30 \%$ respectively), and the other group had the same formation with basalt fiber ( $1 \%$ wt.).

The slurry was poured into prismatic molds with dimension $40 \times 40 \times 160 \mathrm{~mm}$ for flexural strength test and cubic molds with dimension $50 \times 50 \times 50 \mathrm{~mm}$ for compressive strength test; vibrator was used to remove the entrained air. After $24 \mathrm{~h}$ all specimens were de-molded and then cured in an electric oven at $60^{\circ} \mathrm{C}$ for $72 \mathrm{~h}$. At the end of the curing process, all samples were stored at the ambient temperature until the testing day. Mix proportion of geopolymer and patterns are detailed in Table 3 and 4.

Table 3. Mix Proportions Design of Geopolymer (g)

\begin{tabular}{lllll}
\hline Metakaolin & Standard sand & Slag & $\mathrm{NaOH}(10 \mathrm{M})$ & $\mathrm{Na}_{2} \mathrm{SiO}_{3}$ \\
\hline 450 & 1125 & 60 & 150 & 300 \\
\hline
\end{tabular}


Table 4. Mixing Patterns.

\begin{tabular}{cccc}
\hline Mix ID & Metakaolin \% & Colemanite \% & Basalt Fibers \% \\
\hline MK & 100 & - & - \\
$10 \mathrm{C}$ & 90 & 10 & - \\
$20 \mathrm{C}$ & 80 & 20 & - \\
$30 \mathrm{C}$ & 70 & 30 & - \\
$10 \mathrm{C}+\mathrm{B} . \mathrm{F}$ & 90 & 10 & 1 \\
$20 \mathrm{C}+\mathrm{B} . \mathrm{F}$ & 80 & 20 & 1 \\
$30 \mathrm{C}+\mathrm{B} . \mathrm{F}$ & 70 & 30 & 1 \\
\hline
\end{tabular}

MK: Metakaolin, C: Colemanite, B.F: Basalt fiber

\subsection{Characterization}

The compressive strength test was conducted on cubes, after 7 and 28 days according to ASTM C 109 [20]. Flexural strength test was carried out on prism samples at age 7 and 28 days by using standard three- point-bending test according to ASTM C 348 [21].

\section{Results and discussions}

\subsection{Strength properties}

\subsubsection{Compressive strength}

The results of compressive strength of all mix patterns are shown in the Fig 1 and Table 5 .

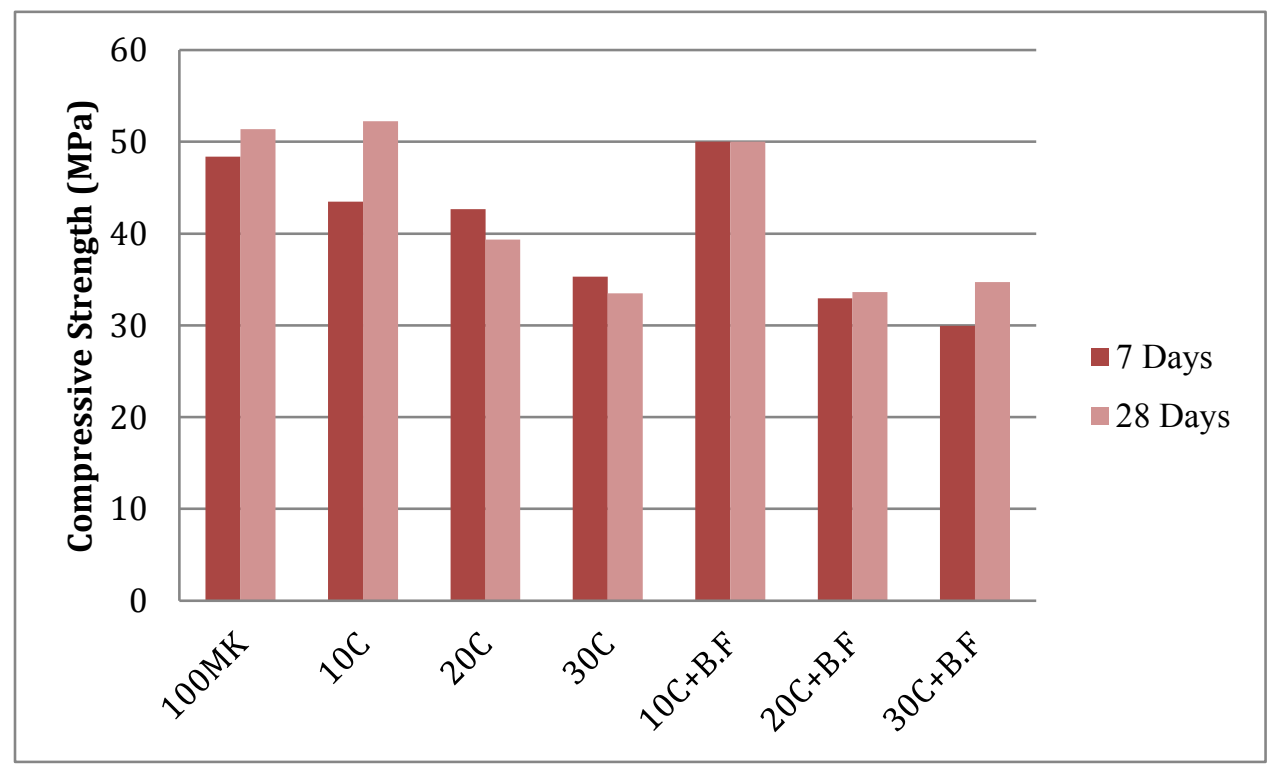

Fig. 1. The compressive strengths of the mixes 
Table 5. Compressive Strength Results of 7 and 28 days

\begin{tabular}{c|cccc}
\hline \multirow{2}{*}{ Mix ID } & \multicolumn{4}{|c}{ Compressive strength } \\
\cline { 2 - 5 } & 7 days Strength & \multicolumn{3}{c}{28 days Strength } \\
& $(\mathrm{MPa})$ & C.R $\%$ & $(\mathrm{MPa})$ & C.R $\%$ \\
\hline $\begin{array}{c}\text { 100 MK } \\
\text { (control) }\end{array}$ & 48.37 & - & 51.38 & - \\
$10 \mathrm{C}$ & 43.48 & -10.11 & 52.26 & 1.71 \\
20C & 42.65 & -11.83 & 39.37 & -23.37 \\
30C & 35.3 & -27.02 & 33.51 & -34.78 \\
10C+B.F & 50.02 & 3.41 & 50 & -2.69 \\
20C+B.F & 32.97 & -31.84 & 33.63 & -34.55 \\
30C+B.F & 29.94 & -38.1 & 34.72 & -32.43 \\
\hline
\end{tabular}

C.R (Changing Ratio) $\%=[($ strength of the sample - strength of control sample)/strength of control sample $] * 100 \%$.

As is shown in the results, replacing metakaolin with colemanite reduced the compressive strength of 7 days samples and this reduction in the strength increased with the increasing of the amount of colemanite in the mixes. The strength decreased almost $30 \%$ in the non-fibrous mix with $30 \%$ colemanite. In fiber reinforced samples, it was observed a slight increase in compressive strength with the sample $10 \%$ colemanite. At the age 28 days, in the non-fibrous sample, the mix with $10 \%$ colemanite showed high increase in the strength comparing to the age 7 days, and it was also slightly higher than the reference mix. In fibrous mixes, the sample of $10 \%$ colemanite showed strength close to the reference one. The other samples with $20 \%$ and $30 \%$ content of colemanite showed higher reduction than non-fibrous samples with the same content of colemanite.

\subsubsection{Flexural strength}

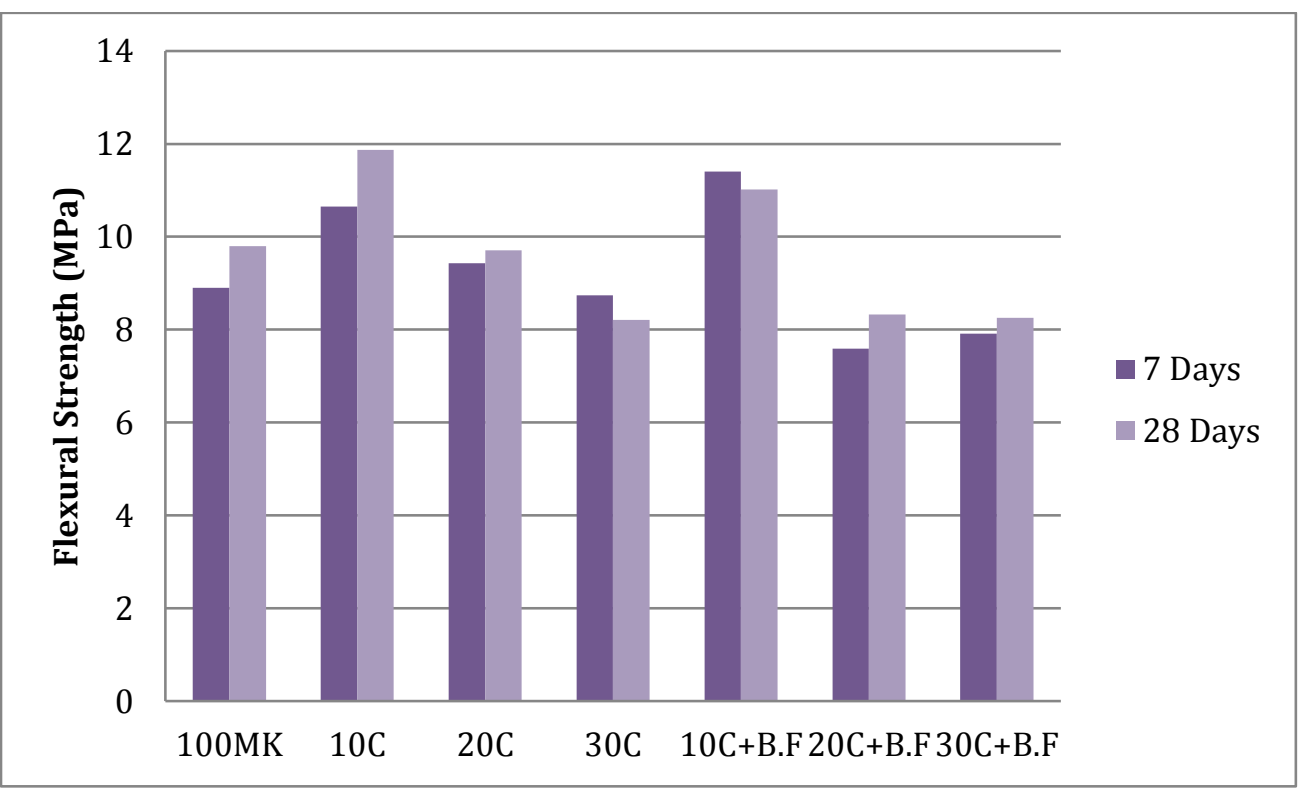

Fig. 2. The flexural strengths of the mixes 
Table 6. Flexural Strength Results of 7 and 28 days

\begin{tabular}{c|cccc}
\hline \multirow{2}{*}{ Mix ID } & \multicolumn{4}{|c}{ Flexural strength } \\
\cline { 2 - 5 } & $\begin{array}{c}\text { 7 days Strength } \\
(\mathrm{MPa})\end{array}$ & C.R $\%$ & $(\mathrm{MPa})$ & C.R $\%$ \\
\hline $100 \mathrm{MK}$ (control) & 8.901 & - & 9.798 & - \\
$10 \mathrm{C}$ & 10.649 & 19.64 & 11.868 & 21.13 \\
20C & 9.43 & 5.94 & 9.706 & -0.94 \\
30C & 8.74 & -1.81 & 8.211 & -16.2 \\
10C+B.F & 11.408 & 28.17 & 11.017 & 12.44 \\
20C+B.F & 7.59 & -14.73 & 8.326 & -15.02 \\
30C+B.F & 7.912 & -11.11 & 8.257 & -15.73 \\
\hline
\end{tabular}

Fibers, in general, have the ability to increase the flexural strength of geopolymer. Back to the results, at the age 7 days, it was noticed that non-fibrous mixes with colemanite showed higher flexural strength than the control mix, like the sample with $10 \%$ colemanite had $20 \%$ increase in terms of flexural strength. Adding basalt fiber to the mix had a good improvement at the age 7 days in the mix of $10 \%$ colemanite with basalt fiber, reached up to $30 \%$ and $11.408 \mathrm{MPa}$ comparing to the control mix, however the other mixes with higher content of colemanite had a reduction with more than $10 \%$ of the flexural strength. At the age 28 the best results were in the mixes; $10 \%$ colemanite and $10 \%$ colemanite with basalt fiber (11.868 and 11.017 MPa respectively).

\section{Conclusion}

Colemanite is considered as a waste material and could be used as partial replacement material. The results showed:

1. Replacing metakaolin with colemanite up to $10 \%$ by weight could give positive results. On the other hand, using colemanite more the $10 \%$ wt. adversely affects the mechanical strengths in general.

2. The reduction caused by using colemanite up to $20 \%$ wt. yielded acceptable results in terms of compressive strength; also it showed an increase in the flexural strength.

3. Basalt fiber had an important improvement in terms of flexural strength in the mix where the colemanite content did not exceed $10 \%$ wt. The increase reached $30 \%$ higher than the reference mix.

\section{References}

1. Klein, Manfred and Donald Rose, "Development of CME National Emission Guidelines for Cement Kilns" in CANMET/ACZ International Symposium on Sustainable Development of the Cement and Concrete Industry, editorV.M.Malhotra, Ottawa, October 1998, pp. 16-30.Klein, Manfred and Donald Rose, "Development of CME National Emission Guidelines for Cement Kilns" in CANMET/ACZ International Symposium on Sustainable Development of the Cement and Concrete Industry, editorV.M.Malhotra, Ottawa, October 1998, pp. 16-30.

2. D. N. Huntzinger., T. D. Eatmon. A life-cycle assessment of Portland cement manufacturing: comparing the traditional process with alternative technologies. In Journal of Cleaner Production 17 (2009) 668-675.

3. M. Stajanča and A. Eštokova. "Environmental Impacts Of Cement Production” University of Košice, , (2012)

4. T. W. Bremner "Environmental Aspects Of Concrete Problems and Solutions" in $1^{\text {st }}$ All-Russian Conference on Concrete and Reinforced Concrete, (2001).

5. Joseph Davidovits."Geopolymers: Inorganic Polymeric New Materials", in Thermal Analysis Journal, Saint Quentin, France, (1991).

6. Joseph Davidovits."Environmentally Driven Geopolymer Cement Application”, in Geopolymer conference, Melbourne, Australia, (2002).

7. A. Palmo., M. W. Grutzeck. And M. T. Blanco. "Alkali-activated fly ashes A cement for the future" in Cement and 
Concrete Research,Spain,(1999).

8. Joseph Davidovits."Geopolymer Cement”, Institute of Geopolymer, France, (2013).

9. A. Palmo., P. Krivenko., I. Garcia-Lodeiro., E. Kavalerova., O. Maltseva and A. Fernandez-Jimenez., " A review on alkaline activation: new analytical perspectives" in construction materials journal., Madrid, Spain ,(2014).

10. H. Rahier, B. Van Mele and J. Wastiels. Low-temperature synthesized aluminosilicate glasses J.Mater.Sci.31 80-85 (1996).

11. Joseph Davidovits. Geopolymer Chemistry and Application, Institute of Geopolymer, Quentin, France - 4th edition (2008)- 393.

12. S. Das, and P. Saha.," Sustainable and Durable Mortar/Concrete Using Geopolymer". $3^{\text {rd }}$ World conference on Applied Science, Engineering and Technology, Nepal, (2014).

13. G. Hemanaag, and B. S. R. K. Prasad.," Geo-polymer Concrete using Metakaolin, Fly-Ash and their comparision". International Journal of Engineering Research and Technology., India, (2014).

14. S. E. Wallah and B. V. Rangan, "Low -calcium fly ash based geopolymer concrete: long-term properties", Research Report GC2, Faculty of Engineering, Curtin University of Technology, Perth, Australia, 2006, pp. 1-97.

15. P. Behera, V. Baheti, J. Militky and P. Louda. "Elevated temperature properties of basalt micofibril filled geopolymer composites", in Construction and Building Materials, 2018.

16. E. Rill, D. R. Lowry, and W. M. Kriven. "Properties of Basalt Fiber Reinforced Geopolymer Composites", Departement of Material Science and Endineering, University of Illinois at Urban-Champaign, Urbana, USA.

17. L. Chen, Z. Wang, Y. Wang and J. Feng. "Prepartion and Properties of Alkali Activated Metakaolin-Based Geopolymer", in Materials journal, (2016).

18. L. Aponte, R. Gutierrrez, and A. Ramirez. "Metakaolin-Based Geopolymer withAdded $\mathrm{TiO}_{2}$ Particles: Physicomechanical Characteristics",Editor : S. Gross, in Coatings Journal, (2017).

19. A. Celik, and G. Cakal. "Characterization of Espey Colemanite and Variation of its Physical Properties with Temperature", in Physicochemical Problems of Mineral Processing Journal, Ankara, Turkey, (2014).

20. ASTM C109/109M, Standard Test Method for Compressive Strength of Hydraulic Cement Mortars, Annual Book of ASTM Standards (Using 2-in. or [50-mm] Cube Specimens, 1. Chemical Analysis, (C109/C109M - 11b), 2010, pp 1-9.

21. ASTM C348, Standard Test Method for Flexural Strength of Hydraulic Cement Mortars, Annual Book of ASTM Standards, 1998, pp 2-7. 